\title{
Nutrición y Nutrición Clínica como derechos humanos
}

\author{
Nutrition and Clinical Nutrition as human rights \\ Nutrição e nutrição clínica como direitos humanos
}

Rocco Barazzoni ${ }^{{ }^{*}}$

https://doi.org/10.35454/rncm.v2supl1.028

No hay duda de que los seres humanos tienen derecho a la nutrición y a la hidratación como soporte básico para la vida. La privación prolongada de cantidad suficiente de alimento da como resultado el desarrollo de desnutrición, el deterioro de la salud, lo que compromete la supervivencia del individuo. Más específicamente, la enfermedad (en particular las infecciones por pérdida o deficiencia de la defensa inmune), las discapacidades $y$, en última instancia, la muerte son consecuencias comunes de la desnutrición. Existe una fuerte conciencia generalizada de que el derecho a ser alimentado se ve comprometido por obstáculos naturales, sociales y económicos que todavía afectan a una gran proporción de la humanidad, pero afortunadamente decreciente. Por lo tanto, garantizar una disponibilidad adecuada de alimentos para todos es una prioridad importante en las agendas políticas de todo el mundo.

Sin embargo, se reconoce mucho menos que el deterioro del estado nutricional y el inicio de la desnutrición se asocian en especial a la enfermedad, independientemente de la disponibilidad de nutrientes e incluso la ingesta. A medida que se enferman y son vulnerables, los humanos a menudo desarrollan anorexia, disminución del apetito, así como profundos trastornos metabólicos que afectan la capacidad de utilizar alimentos y nutrientes para almacenar energía y preservar los tejidos y la masa muscular. Lo más importante es que la desnutrición relacionada con la enfermedad es aún más peligrosa para

\footnotetext{
1 Departamento de Ciencias Médicas, Quirúrgicas y de Salud Universidad de Trieste - Italia

*Correspondencia: Rocco Barazzoni barazzon@units.it
}

la supervivencia del paciente, ya que aumenta los riesgos específicos de la enfermedad. Por lo tanto, el derecho a la nutrición se vuelve crucial en las condiciones de la enfermedad, pero desafortunadamente los componentes nutricionales y las complicaciones de la enfermedad son subestimados en forma dramática. La calidad de los alimentos y la ingesta de estos en los entornos hospitalarios a menudo son bajos debido a la selección y prioridades de las instituciones de salud que descuidan las necesidades nutricionales, en un momento en que los pacientes deberían recibir la máxima atención y cuidado. Los pacientes que no pueden ingerir cantidades adecuadas de calorías y proteínas podrían, y deberían ser tratados con una nutrición suplementaria para satisfacer sus necesidades y preservar el estado nutricional. Los protocolos de nutrición clínica están disponibles para este objetivo a través de rutas y técnicas orales, enterales y parenterales, que se introdujeron hace varias décadas y se ha venido perfeccionando a través del tiempo. Sin embargo, la terapia nutricional es muy poco reconocida e implementada en los diferentes campos médicos. Descuidar e incluso ignorar la opción terapéutica de la nutrición clínica es cada vez más frustrante y, en última instancia, inaceptable, ya que se acumulan pruebas sólidas que demuestran su efectividad para reducir complicaciones, mortalidad y ahorrar costos de atención médica.

Por esta razón, a medida que la disciplina de la nutrición clínica se desarrolla tan rápidamente, las sociedades científicas de nutrición clínica reconocen cada vez más la necesidad de ampliar sus alcances más allá de apoyar y difundir la excelencia en investigación, educación y práctica clínica. De hecho, deberían promover cada vez más acciones para aumentar la con- 
ciencia sobre la importancia de prevenir la desnutrición y sus complicaciones dramáticas en todos los pacientes y entornos clínicos. Dichas acciones deben tener como objetivo llegar no solo a los profesionales de la salud, sino también a los pacientes, los encargados de formular políticas y al público en general a través de campañas estratégicas multifocales. Como esto ocurre cada vez más en el mundo, la Federación Latinoamericana de Terapia Nutricional, Nutrición Clínica y Metabolismo (FELANPE) implementó un paso importante que condujo a la Declaración de Cartagena este año, llamando a reconocer formalmente que la nutrición clínica, no diferente de los alimentos básicos, es un derecho humano. La Declaración de Cartagena fue firmada por todos los presidentes de las sociedades que conforman la FELANPE. Los presidentes de La Sociedad Europea de Nutrición Clínica y Metabolismo (ESPEN), así como de la Sociedad Americana de Nutrición Enteral y Parenteral (ASPEN) fueron invitados a Cartagena a firmar como testigos. La Declaración de Cartagena también proporciona indicaciones importantes para avanzar hacia la implementación de sus principios. El reconocimiento formal y generalizado de la nutrición clínica como un derecho humano fundamental podría desempeñar un papel relevante en la promoción de la conciencia de que la desnutrición relacionada con la enfermedad es una carga clínica importante, reduciendo la esperanza de vida, la calidad de vida y los recursos de atención médica en millones de pacientes en todo el mundo.

La Sociedad Europea de Nutrición Clínica y Metabolismo ha reconocido la necesidad de promover iniciativas para aumentar la conciencia y la implementación de la terapia nutricional, que también debe llegar a los pacientes, al público en general y a los políticos responsables. En consecuencia, ESPEN apoya firmemente todos los esfuerzos para reconocer el derecho de cada paciente a la nutrición y la nutrición clínica y, por lo tanto, firmó de forma convincente la Declaración de Cartagena en calidad de testigo. 